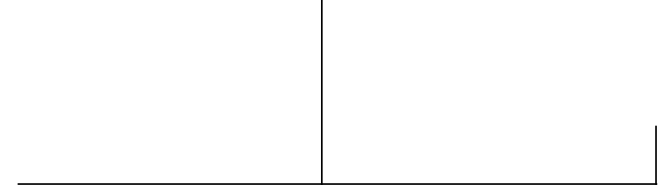

Rev. Latinoam. Psicopat. Fund., VI, 4, 157-163

\title{
Apresentação
}

\section{A atualidade da instituição psiquiátrica}

\author{
Eduardo de Carvalho Rocha
}

Esta é uma ocasião especial, pois estamos aqui reunidos para dar início a este Seminário em que comemoramos os cinqüenta anos de existência de Jurujuba e nos dispomos a tentar delimitar alguns dos desafios que temos adiante em nosso futuro. É até compreensível que não se queira mais comemorar a existência de hospitais psiquiátricos, face aos destinos desastrosos em que a grande maioria se embaraçou. No entanto, a falência de certos modos de institucionalização não quer dizer que podemos dispensar-nos dessas instituições. Por exemplo, a imperfeição e os conflitos dos regimes democráticos não nos induzem a pensar que a democracia deva ser abolida. Do mesmo jeito que os graves problemas que temos no sistema de segurança pública não significa que devamos renunciar a cuidar da segurança do cidadão. Nos dias de hoje, face ao caráter segregador e excludente no qual se mantiveram muitos desses hospitais, acabou não sendo relevante comemorar a existência de um hospital psiquiátrico, ao contrário, espera-se festejar o seu fechamento e a sua substituição pelos dispositivos comunitários de atenção em Saúde Mental.

Então, estamos aqui na contramão dessa corrente, porém não em posição antagônica, comemorando um tempo de existência desta instituição, e procurando refletir sobre sua função e lugar num tempo em que o próprio objeto da psiquiatria vem sofrendo grandes mudanças, e em particular abandonando o terreno da doença mental e se postulando aquele outro da saúde mental. Mas, afinal, o que será esse objeto da Saúde Mental? Será o que diz respeito ao cidadão adequadamente integrado ao 
senso comum? Por enquanto seria prudente considerá-lo um terreno de práticas dirigidas aos pacientes psiquiátricos, visando engajá-los na vida civil por meio dos diversos dispositivos de atenção comunitária que possam vir a ser agenciados pelos profissionais médicos, psicólogos, enfermeiros, assistentes sociais, terapeutas ocupacionais e alguns outros. Ainda aí verificamos que um apelo ao hospital psiquiátrico não é raro, o que só aumenta a responsabilidade dos "clínicos de hospital” (poderíamos nos chamar assim?) em relação à forma de sua condução clínica frente a cada caso, agora num contexto de tratamento desejavelmente articulado com essa rede de serviços e profissionais. De todo jeito, não podemos deixar de partir do fato de que há demanda ao hospital, seja ela dos próprios pacientes, dos colegas dos outros serviços, dos familiares, da polícia, da assistência social, e enquanto ela existir, precisamos estar aí para responder com nosso melhor, e é sobretudo ao trabalho incansável desses profissionais que têm procurado manter vivo este lugar, por reconhecê-lo como demandável, que rendemos nossa homenagem.

Gostaria ainda de esclarecer que esta minha fala não se destina a avivar nossa memória sobre o Hospital de Jurujuba. Isso será feito em outro momento, principalmente pelo testemunho de alguns personagens-chave de sua história. $\mathrm{O}$ que me interessa aqui é atualizar algumas questões sobre a função da psiquiatria já que, no contexto da reforma de seu aparato institucional, corre-se o risco de ela própria acabar sendo destruída. É claro que isso pode ser visto como o melhor resultado que se poderia esperar da reforma, que seria o de liberar a loucura das amarras do saber psiquiátrico recolocando-a numa relação supostamente mais tolerante com a sociedade, posição da qual divergimos. E por que divergimos disso? Porque me parece que esse projeto de uma relação harmoniosa da sociedade com a loucura é um sonho. Sabemos que no mundo antigo e medieval os loucos também estavam submetidos às leis da pólis, que em alguns momentos podia ser mais tolerante e, em outros, cruel. O conflito, o mal-estar, o horror, são comuns nessa relação, e não vejo qual seria a vantagem de supor um estado de equilíbrio social que atenuasse esse regime.

Pretendo atualizar essas questões perguntando em nome de que (ou de quem) dissolveríamos esse lugar? Seria bom também que refletíssemos sobre esse eventual esvaziamento, da psiquiatra, no contexto do crescente avanço de uma vida dominada pela tecnologia por um lado, e pelo senso comum de outro.

A primeira questão que levanto tem relação com a autorização do psiquiatra. De onde ele se autoriza? O segundo ponto que abordarei nos levará a interrogar se as condições dessa autorização se mantêm as mesmas desde a sua fundação, e em sendo demonstrado que tais condições se alteraram, desde onde vamos nos sustentar para orientar nossa práxis? 


\section{ENTREVSTA}

ano $\mathrm{VI}$, n. 4, dez/ 2003

O psiquiatra sempre foi visto como um sujeito sombrio, esquisito, estranho, tratado com um misto de reverência e de derrisão, e dele sempre se procurou manter uma certa distância, já que sua presença atualizava o estigma da loucura, dos atos insensatos, da segregação. Os alienistas do século XIX ao criarem os primeiros lugares de tratamento foram estabelecendo as bases do saber psiquiátrico, buscando, mediante a observação detalhada dos pacientes, delimitar os fundamentos dessa ciência. A psiquiatria deu início a seu processo de constituição num tempo em que o homem era prisioneiro de psicologias que consideravam a existência de uma mente como uma tela onde a alma se projetava. A verdade da mente eram os valores morais e religiosos. Era deles que emanava o próprio funcionamento mental, se é que podemos falar de "mental” naquela época, e inclusive os primeiros psiquiatras se inscrevem postulando a necessidade de se forjar uma linguagem própria para apreender o objeto da psiquiatria. Objeto esse que precisaria ser formalizado em termos novos, não mais aqueles dos escolásticos, mas como uma ciência natural, isto é, com termos que estivessem sujeitos a operações de verificação e contestação metódica. Não mais como uma visão de mundo, mas como uma ciência. É essa posição que retira a loucura do lugar do senso comum, e a circunscreve à medicina, com todas as conseqüências que daí advieram. O que estava em jogo era compreender ou explicar a própria irracionalidade, os fracassos da razão, pelo funcionamento de um aparato próprio, o aparelho psíquico, e de suas relações com o corpo. Assim, o que passa a responder pela mente não é mais a alma e sim o jogo de interação de idéias, de circuitos nervosos, de processos de comunicação.

Então a psiquiatria se autoriza por um mandato social que estabelece que as coisas devem funcionar, que os homens devem estar aptos a exercer sua liberdade num mundo sujeito a uma nova ordem, aquela instituída pela Revolução Francesa e progressivamente comandada pela ciência e pelo capitalismo. Se não puderem exercê-la, que pelo menos não perturbem demais a vida dos outros. Mas de todo modo a assunção de atos, isto é, o exercício da vontade, passa a estar condicionada para esse novo homem por uma rede simbólica que funciona de maneira própria, tem ciência, e não mais dirigida por valores universais herdados ou recebidos diretamente de instâncias divinas. O homem se libera de Deus para se verificar como sujeito, como assujeitado a operações que o produzem. Essa liberação traz consigo a idéia de conflito, de traumatismo, no advento desse homem, e é interessante notar como nesses momentos germinais da psiquiatria encontramos nossos alienistas refletindo sobre o funcionamento mental e considerando o conflito entre idéias como o modo que acabava conduzindo ao adoecimento mental. Primeiro eram as causas morais que repercutiam no sistema nervoso, no corpo portanto; depois, eram as idéias em conflito que geravam o desequilíbrio e o transtorno. 
A psiquiatria se estabeleceu no momento em que foi concebido um sujeito livre que se representava a si mesmo, e sua nosografia foi organizada em torno das relações desse sujeito com o mundo, isto é, em torno das formas peculiares que ele foi levado a assumir num jogo social de múltiplas determinações. Os psiquiatras ganham existência para, a partir daí, fazer o trabalho de catalogação dessas formações e no bojo dessa investigação se encontraram com quadros que mostravam uma estabilidade, e assim nomearam a doença mental. Não uma única, mas diversos quadros que foram apreendidos e descritos em quase sua totalidade nesse período dos clássicos. Apesar da diversidade, e das variadas interpretações e explicações, essa prática instituiu uma discursividade que sempre esteve referida aos fatos que rompem com o discurso comum, sejam eles fatos de discurso propriamente ditos, ou atos, por exemplo, como suicídio, assassinatos, abusos físicos sobre outrem, alterações de humor, entre outros. O que sempre demarcou essa discursividade é o fato de ela dizer respeito ao que está em discordância, em default, com o discurso comum. Não exclusivamente uma discordância de conteúdo, semântica, mas essencialmente aquela de cunho formal, sintático. O nascimento da psiquiatria trouxe como conseqüência a emergência no social do louco como um ser passível de inscrição em sua diferença, como aquele que freqüenta o discurso de forma peculiar, ou melhor, como aquele que não freqüenta o discurso comum senão de forma problemática. O mais importante é que isso constitui uma discursividade porque pode ser escrita, formulada.

Esses pontos que estou salientando é para enfatizar que a psiquiatria nasceu do mesmo movimento que instituiu um outro tipo de dominância de discurso, o da ciência, e veio a ocupar o seu lugar demarcando a diferença entre a loucura e o discurso comum. Sua autorização vem daí, do fato de ter sustentado, na ciência, a discursividade, seus dispositivos e procedimentos, advertindo sobre essa fronteira entre o normal e o patológico. Mais que advertindo, estabelecendo com seus termos uma discursividade que tornou possível operar. É por já se estar neste campo operacional, que se reconhece a problemática da exclusão como relacionada à linguagem, e não mais às possessões e às influências demoníacas. Exclusão essa que passa a jogar um papel central no edifício psicopatológico e na montagem das instituições manicomiais. Falar de exclusão não é apenas caracterizá-la como uma atitude social de preconceito, e sim tratála de forma lógica como dizendo respeito ao que cai em uma operação, que se perde, que não entra na cadeia. O preconceito é uma de nossas afetações ao que retorna da exclusão, não é de forma alguma a única, e se podemos hoje reconhecer outras modalidades por onde a exclusão opera, devemos isso em grande parte ao trabalho dos psiquiatras. Quem melhor pôde descrever certos fenômenos nos quais uma parte do corpo é excluída, cortada fora? Quem melhor 


\section{ENTREVSTA}

ano $\mathrm{VI}$, n. 4, dez/ 2003

pode nos apontar para as dramáticas incidências do seqüestro de nossos órgãos como as que encontramos na clínica das depressões?

Bem, os tempos mudaram, assim como aquele discurso que começava a nascer expandiu-se tanto que passou a reger o laço social, e hoje devemos nos perguntar se ainda estamos autorizados pelas mesmas razões que aqueles nossos antecessores. Por exemplo, quando os psiquiatras passam a freqüentar os jornais e TVs como conselheiros do comportamento, ainda se trata do mesmo mandato e da mesma resposta que antes?

Vejamos algumas diferenças. No final do século XVIII e início do XIX tratou-se de fundar um campo cuja fronteira foi estabelecida ali mesmo onde os fenômenos de exclusão se articularam à linguagem, à relação do homem com sua própria fala. Isso possibilitou o isolamento de várias situações clinicamente diferenciadas em que foi possível reconhecer o funcionamento fisiológico da linguagem e sua dominância sobre as chamadas funções intelectuais tais quais a inteligência, o raciocínio, o juízo, a afetividade, em suma sobre o discurso comum, o do bom senso. A psiquiatria, e posteriormente a psicanálise, retiraram do eu o centro da vida mental, o que quer dizer, colocaram em questão esse bom senso. A primeira, ao isolar formações psicopatológicas que demonstravam um funcionamento não condicionado pelas categorias de identificação, unidade, síntese. A segunda, ao revelar-nos no inconsciente a função do sem-sentido. É bem verdade que ambas "reabilitaram" o reino do eu tanto pelo cognitivismo como pela psicologia do ego. De qualquer modo, o real da loucura recebeu um lugar simbólico que não a dissolvia no discurso comum, ao contrário, a mantinha guardada, como em reserva dessa impossibilidade de reduzi-la ao funcionamento da realidade. O movimento da reforma vai incidir precisamente sobre essa reserva, propondo uma outra forma de tratar esse real, isto é, propondo outros dispositivos de tratamento desse real e questionando as próprias relações da sociedade com esse discurso excluído. Quer dizer, essa é minha maneira de ler e de me situar na reforma.

Agora, neste final de século XX e início do XXI vivemos um tempo de dissolução de fronteiras, de unificação de linguagens e de globalização de mercados, e diversamente daquele período inicial quando o discurso comum era agenciado pela palavra dos políticos e de alguns mestres, mestres e não professores, é bom que se diga, hoje ele é agenciado pelas corporações e pela imagem, e não mais pela palavra. E entre as características desse discurso está a dissolução das diferenças, o tratamento de todos como iguais e com plenos direitos para viverem da maneira mais confortável e satisfatória, e também a dissolução das barreiras entre normal e patológico. Isso pode acabar fazendo com que nos deixemos ser levados por esse comando, e que tratemos aquele real da loucura, que antes tinha uma inscrição, como uma questão administrativa, que pode ser absorvida no social sob uma eficiente gestão econômica e política. 
Nesse contexto quais serão, atualmente, o mandato e as formas de legitimação da psiquiatria?

$\mathrm{O}$ argumento que estou procurando perseguir é que apesar de todo o ideal científico, naturalista e mecanicista dos primeiros tempos, os psiquiatras clássicos não foram insensíveis à relação entre loucura e linguagem. A bem da verdade, vários deles escreveram extensos trabalhos sobre o assunto, como foi o caso de Kahlbaum, Bleuler, Kraepelin, Seglas, entre outros, marcando as particularidades discursivas, linguageiras, das psicoses. Todo esse arcabouço clínico foi erguido em torno de fenômenos como neologismos, mutismo, pensamentos automáticos, frases interrompidas, ordens ouvidas, delírios de diferentes temas, roubos e interrupções de pensamentos, entre vários outros. A clínica que sustentou esse trabalho foi a da observação meticulosa, das anotações, e de algumas interpretações. Muitos dizem que essa clínica era orientada pelo olhar, mas eu prefiro dizer que era principalmente pela escuta e pela escrita. Escreviam muito o que ouviam e viam, e na medida em que iam pondo as coisas no papel, isso ia fazendo um texto. Era uma clínica do relato, mas não do relato testemunhal de quem apenas observa um acontecimento, e sim do relato de uma articulação entre o que o paciente dizia ou agia, e aquilo que interrogavam, mas principalmente era um escrito. Para alguns clínicos dessa época somente uma entrevista cuidadosamente conduzida poderia fornecer os elementos do quadro, sem a qual a psicose passava despercebida ou disfarçada, o que não quer dizer inexistente.

Então a psiquiatria se forjou nessa práxis de linguagem em que o clínico foi estabelecendo a moldura, o enquadramento para que se evidenciassem os quadros onde os diversos fracassos de funcionamento no discurso comum pudessem aparecer. O que isso quer dizer? Que esse discurso comum não é fechado, não é completo, não se realiza sem problemas, e, até mais, que se realiza sob determinações absolutamente estranhas ao nosso conhecimento, à nossa racionalidade. As psicoses apontam para o limite desse discurso. Esta tem sido a obra da psiquiatria: demonstrar em sua clínica os limites do discurso comum, o que quer dizer que ele não pode tudo, que ele não é mestre absoluto. Isto quer dizer que o psicótico é um revolucionário? De maneira alguma, isso quer dizer somente que ele repercute os limites de um discurso, mas isso não é o mesmo que colocá-lo em posição de revolucioná-lo.

Voltando à atualidade, será que podemos continuar sustentando que essa função da psiquiatria continua operando? Será que o psiquiatra ainda é aquele que vela para que esses limites sejam reconhecidos, identificados, levados em conta, respeitados? É bem verdade que por muito tempo os próprios psiquiatras confundiram esse estado de exclusão, de fora do discurso comum, como tendo um único destino, ou seja, o da exclusão da vida social, mas é preciso ter claro que uma precede a outra. É a posição de exclusão no discurso que é causa da 


\section{ENTREVSTA}

ano $\mathrm{VI}$, n. 4, dez/ 2003

exclusão social e não vice-versa, e considerar a questão ao inverso é anular, é dissolver a psicose ao discurso comum.

Essa diferenciação é crucial para o futuro da psiquiatria e é justamente isso que me parece estar em questão na atualidade, pois as coisas vêm se arranjando de modo a apagar essas diferenças, de modo a considerar que não há nada mais a avançar no terreno da psicopatologia e da clínica que não seja o desenvolvimento de drogas ou de exercícios cognitivos de conscientização. Com isso o psicótico vai ficando cada vez mais "normal" e adaptável ao discurso comum. Está aí uma coisa com que quase todos iriam concordar, não é mesmo? Afinal, não seria isso a vitória da ciência sobre o obscurantismo? Uma vitória do saber e da política de direitos humanos, em que uma sociedade mais justa e tolerante finalmente estaria disposta a não excluir seus loucos. O problema é o preço que se vai pagar por essa "normalização", preço esse que pode acabar tendo como conseqüência uma nova forma de exclusão, uma exclusão normalizada. Nos primórdios coube aos psiquiatras inventar os operadores e os dispositivos para se lidar com o estranhamento que a loucura produzia no social. Agora parece que eles estão cada vez mais constrangidos a apagar qualquer manifestação de estranhamento.

A que está constrangido o psiquiatra atualmente? Principalmente a aliviarnos da existência. Existir é problemático, difícil, penoso, desagradável, trabalhoso, incompreensível. E o que nos pedem então? Que tenhamos um remédio para aliviar dessa existência. Não disse aliviar essa existência, o que seria muito diferente já que justamente, por ser a existência difícil é que é, às vezes, necessário encontrar algum alivio no caminho. Algum alívio, e não ausência de sofrimento.

Também estamos constrangidos a saber, a explicar tudo o que acontece no cotidiano. Por que amamos, por que morremos, por que nos tornamos pais, ou neuróticos, ou psicóticos. Tudo tem um saber a que se pode recorrer, e nós psiquiatras estamos constrangidos por esse imperativo do atual discurso comum a saber cada vez mais. "Saibam mais" sobre o cérebro, sobre a infância, sobre os modos de raciocínio, sobre o pensamento psicótico, neurótico, normal etc. Saibam mais e transformem esse saber em mercadoria a ser distribuída pelos jornais, pela TV, pela internet.

Mas eu penso que os psiquiatras podem fazer um pouco mais do que apenas se submeterem a esse imperativo, e uma dessas coisas é continuar tentando escrever, formulando os tipos clínicos que passam a dominar nossa atualidade social. Em vez de ficarem dormindo, ou obedecendo cegamente a esse comando, eles deveriam se pôr a elucidar a relação dos quadros clínicos que hoje prevalecem, tais como as toxicomanias, as depressões, os transtornos alimentares, a paranóia social, com o tipo de laço social dominante.

Como vêem temos muito trabalho pela frente ainda. 